\title{
The system of industrial boiler waste heat and solar energy increasing the temperature of biogas digester
}

\author{
Bokang Yan ${ }^{1, a}$ \\ ${ }^{1}$ North China Electric Power University, Baoding 071000, China; \\ ayanbokang1994@outlook.com
}

Keywords: biogas digester, solar energy, industrial boiler waste

\begin{abstract}
In this paper, aiming at the problem of fermentation northern winter weather is not conducive to the biogas system, we have designed a set of Solar energy and industrial waste heat boiler flue gas complex warming systems to ensure that biogas systems in the winter can also be normal fermentation. This system solved the problem which we can't make good use of the waste heat of Industrial boiler. By comparing the heat loss to the warming effect of biogas system, this system can ensure the stable operation of the biogas project. This paper provides a reference to construct new type of biogas digester in North China.
\end{abstract}

\section{Introduction}

The use of methane in gas production and consumption in North China is less than it in South China. The differences between the northern and southern biogas utilization are temperature differences.

The study found that biogas can be produced from 10 to 60 degrees. When temperature is over $10{ }^{\circ} \mathrm{C}$, biogas is increasing rapidly. Microbes are very sensitive to temperature changes. If the temperature changes suddenly, gas production will cut down. When it is in winter in North China, the temperature is so low that biogas digester can’t produce enough biogas.

\section{The design of system}

The system of industrial boiler waste heat and solar energy increasing the temperature of biogas pool divided into three parts: solar heating collection system, flue gas waste heat recovery system and biogas generating system. Solar heating collection system heat the water in the water storage tank with solar energy. Four pipes are arranged to the edge of the biogas digester. Water heated by solar energy and industrial boiler is introduced into the pipeline. The type of heat transfer is Radiation heat transfer and Convective heat transfer. Biogas fermentation system temperature was maintained at 28-38 degrees. Warming system automatically controls temperature with temperature sensor. When the water temperature is lower than 10 degrees, the valve which control cold water pipe become closed to prevent water from cooling the methane tank. When the water temperature is higher than 60 degrees, the valve which control hot water pipe become closed. Flue gas waste heat recovery system collect the flue gas. Firstly, exhaust gas was introduced into the water storage tank. then, the exhaust gas flows into the gas tank disposed in the outer casing. The entrance of the flue gas is at the top of the biogas digester and the export is at the bottom of the biogas digester. This keeps the biogas digester warm.

\section{Energy calculation of temperature increasing system}

\section{Calculation of biogas digester}

After our discussion, a family of four just need a $3 \mathrm{~m}^{3}$ biogas digester to meet the needs of daily life. This system is designed to meet the needs of 100 households. So, we design a biogas digester whose radius is $5 \mathrm{~m}$ and the height is $4 \mathrm{~m}$. Tank volume is $314 \mathrm{~m}^{3}$. And the temperature of the flue gas is stable at 30 degrees. 
Heat loss of biogas tank: $Q_{p}=Q_{b}+Q_{t}+Q_{e}$

$Q_{b}$ is the heat loss at the bottom of the biogas digester; $Q_{t}$ is the heat loss at the top of the biogas digester; $Q_{e}$ is the heat loss on the side of the biogas digester.

Total heat transfer coefficient of multi-layer flat wall $K$ is calculated by the formula:

$$
K=\frac{1}{\frac{1}{h_{1}}+\sum_{i=1}^{3} \frac{\delta_{i}}{\lambda_{i}}+\frac{1}{h_{2}}}
$$

$h_{1}$ :Internal convective heat transfer coefficient; $h_{1}=750 \mathrm{~W} /\left(\mathrm{m}^{2} \bullet \mathrm{K}\right)$

$h_{2}$ :the heat transfer coefficient between the outer surface of the insulation layer and surroundings; $h_{2}=6.812 \mathrm{~W} /\left(\mathrm{m}^{2} \bullet K\right)$

$\lambda_{1}$ : Thermal conductivity of the tank $\lambda_{1}=52 \mathrm{~W} /(\mathrm{m} \bullet \mathrm{K})$

$\lambda_{2}$ : The thermal conductivity of smoke layer $\lambda_{2}=0.0266 \mathrm{~W} /(\mathrm{m} \bullet \mathrm{K})$

$\lambda_{3}$ : The thermal conductivity of insulation material $\lambda_{3}=0.0208 \mathrm{~W} /(\mathrm{m} \bullet \mathrm{K})$

$\delta_{1}$ : The plate thickness of the tank $\delta_{1}=0.01 \mathrm{~m}$

$\delta_{2}$ : Thickness of insulation material $\delta_{2}=0.1 \mathrm{~m}$

$\delta_{3}$ : The safeguard depth $\delta_{3}=0.1 \mathrm{~m}$

Based on calculation, $K_{t}=K_{b}=0.3164 \mathrm{~W} /\left(\mathrm{m}^{2} \bullet K\right)$

Total heat transfer coefficient of multi-layer cylinder $K_{e}$ is calculated by the formula:

$$
K_{e}=\frac{1}{\frac{1}{h_{i}} \cdot \frac{d_{o}}{d_{i}}+\sum_{n=1}^{3} \frac{d_{o n}}{2 \lambda_{n}} \ln \frac{d_{o n}}{d_{\text {in }}}+\frac{1}{h_{o}}}
$$

Based on calculation, $K_{e}=0.1308 \mathrm{~W} /\left(\mathrm{m}^{2} \bullet K\right)$

The heat loss of the biogas tank is

$$
\mathrm{Q}=\mathrm{KA}\left(t_{1}-t_{0}\right)
$$

$A$ : The acreage of heat dissipation surface $m^{2}$

$A_{t}=A_{b}=20.50 \mathrm{~m}^{2}, A_{e}=64.01816 \mathrm{~m}^{2}$

$K$ : Thermal conductivity $\mathrm{W} /\left(\mathrm{m}^{2} \cdot K\right)$

$t_{1}$ : The temperature of the liquid in tank $t_{1}=35^{\circ} \mathrm{C}$

$t_{0}$ : Ambient temperature of mean annual temperature $t_{0}=10^{\circ} \mathrm{C}$

$$
\begin{gathered}
Q_{t}=Q_{b}=69.905 \mathrm{~W}, Q_{e}=209.087 \mathrm{~W} \\
Q_{p}=Q_{b}+Q_{t}+Q_{e}=349.68 \mathrm{~W}
\end{gathered}
$$

\section{Solar collector}

Tube specifications: $\Phi 55 \mathrm{~mm} \times 2000 \mathrm{~mm}$

The number of tubes: $n=42$

Radiation intensity in North China: $E=160 \mathrm{~W} / \mathrm{m}^{2}$

The heat of solar heating collection system is calculated by the formula:

$$
\mathrm{Q}_{S}=\mathrm{AE} \eta_{\mathrm{j}}\left(1-\eta_{s}\right)
$$

$A$ : Collector area $\mathrm{A}=0.055 \times 2 \times 42=4.62 \mathrm{~m}^{2}$

$E$ : Radiation intensity in North China $E=160 \mathrm{~W} / \mathrm{m}^{2}$

$\eta_{\mathrm{j}}$ : Efficiency of collector $\eta_{\mathrm{j}}=0.45$

$\eta_{\mathrm{s}}$ : Pipe heat loss $\eta_{\mathrm{s}}=0.1$

The heat of solar heating collection system is 


$$
\mathrm{Q}_{\mathrm{s}}=299.38 \mathrm{~W}
$$

As we design, the heat which gas give to tank $Q_{g}=50 \mathrm{~W}$. Total energy delivered by the outside to the system is:

$$
Q=Q_{s}+Q_{g}=349.376 \mathrm{~W} \approx Q_{t}=349.68 \mathrm{~W}
$$

The energy from environment is equal to the energy which biogas digester lost. So, biogas digester temperature can be stabilized at 35 degrees.

\section{Systematic Return}

In accordance with the above algorithm, we can calculate the heat loss $Q_{t}=698 \mathrm{~W}$ if we don't use the system of industrial boiler waste heat and solar energy increasing the temperature of biogas digester. We can save electric energy $6115 \mathrm{~kW} \bullet h$. We can save 3180 yuan per year.

\section{Summary}

Aiming at the problems in the utilization of biogas in the northern countryside, this paper put forward a method that we keep the biogas digester warm with industrial boiler waste heat and solar energy. This method can make biogas digester produce large amounts of biogas in winter. It can help energy save the energy.

\section{Reference}

[1]Yuehai Huang, Wei Zhao. Basic conditions of biogas fermentation [J]. New agriculture,2006,09:60.

[2]Xiaogang Xu, Xiufeng Wu. Analysis on the influencing factors of Rural Biogas Development in China[J]. Anhui agricultural sciences, 2008,07:2888-2890.

[3]Xuesheng Wang, Ruzhu Wang, Jingyi Wu, Yixiong Xu. Study on the application of solar energy heating system for crude oil transportation[J]. Oil \& Gas Storage and Transportation, 2004,07:41-45+65-69.

[4]Chenglin Meng, Rongping Li, Xiujin Li. Greenhouse solar water heater combined warming system for sludge anaerobic digestion[J]. Journal of agricultural engineering, 2009,09:210-214. 